\title{
Subinhibitory antimicrobial concentrations: A review of in vitro and in vivo data
}

\author{
George G Zhanel, PharmD, Daryl J Hoban, PhD, Godfrey KM Harding, MD
}

\begin{abstract}
GG ZHANEL, DJ HoBAN, GKM HARDING. Subinhibitory antimicrobial concentrations: A review of in vitro and in vivo data. Can J Infect Dis 1992;3(4):193-201. Antimicrobial activity is not an 'all or none' effect. An increase in the rate and extent of antimicrobial action is usually observed over a wide range of antimicrobial concentrations. Subinhibitory antimicrobial concentrations are well known to produce significant antibacterial effects, and various antimicrobials at subinhibitory concentrations have been reported to inhibit the rate of bacterial growth. Bacterial virulence may be increased or decreased by subinhibitory antimicrobial concentrations by changes in the ability of bacteria to adhere to epithelial cells or by alterations in bacterial susceptibility to host immune defences. Animal studies performed in rats, hamsters and rabbits demonstrate decreased bacterial adherence, reduced infectivity and increased survival of animals treated with subinhibitory antimicrobial concentrations compared to untreated controls. The major future role of investigation of subinhibitory antimicrobial concentrations will be to define more fully, at a molecular level, how antimicrobials exert their antibacterial effects.
\end{abstract}

Key Words: Antimicrobial, Subinhibitory concentrations

\section{Concentrations antimicrobiennes sous-inhibitrices: Analyse des données in vitro et in vivo}

RÉSUMÉ: L'activité antimicrobienne ne suit pas la règle du tout ou rien. On observe habituellement une augmentation de la vitesse et de l'étendue de l'action antimicrobienne sur une large gamme de concentrations antimicrobiennes. Les concentrations antimicrobiennes sous-inhibitrices sont bien connues pour leur action antibactérienne significative et l'on rapporte que, utilisés à des concentrations sous-inhibitrices, divers antimicrobiens empêchent la pousse bactérienne. La virulence des bactéries peut être majorée ou diminuée par des concentrations antimicrobiennes sous-inhibitrices, qui modifient la capacité d'adhérence des bactéries aux cellules épithéliales ou la sensibilité des bactéries aux défenses immunitaires de l'hôte. Des études animales portant sur le rat, le hamster et le lapin démontrent une diminution de l'adhérence bactérienne, un pouvoir infectant moindre, et la survie accrue des animaux traités par des concentrations antimicrobiennes sous-inhibitrices par rapport aux groupes témoins non traités. Dans l'avenir, le rôle principal des concentrations antimicrobiennes sous-inhibitrices sera de définir plus clairement le mode d'action des antimicrobiens au niveau molêculaire.

Department of Medical Microbiology, Faculty of Medicine and Faculty of Pharmacy. University of Manitoba: Health Sciences Centre, St Boniface General Hospital and St Boniface General Hospital Research Centre. Winnipeg, Manitoba

Correspondence and reprints: Dr GG Zhanel, Department of Microbiology. Health Sciences Centre, MS6 - 820 Sherbrook Street, Winnipeg, Manitoba R3A 1R9. Telephone (204) 787-4902, Fax (204) 787-4699

Received for publication July 27, 1990. Accepted March 23, 1991 
A NTIMICROBIAL ACTIVITY IS NOT AN 'ALL OR NONE' EFFECT (1). An increase in the rate and extent of antibacterial action is usually observed over a wide range of antimicrobial concentrations, and within this range the minimum inhibitory concentration (MIC) represents one particular degree of antibacterial effect. Concentrations of antimicrobials that are equal to or greater than the MIC or the minimum bactericidal concentration (MBC) produce dramatic changes in bacteria (2). Subinhibitory antimicrobial concentrations are also widely known to produce antibacterial effects $(1,2)$. In addition, since the actual time of contact between bacteria and antimicrobials at concentrations above the MIC may be relatively short in the blood and especially at sites of infection, subinhibitory antimicrobial concentrations may play an important role in the efficacy of antimicrobials in vivo.

Considerable data have been published describing antibacterial effects due to subinhibitory antimicrobial concentrations. The purpose of this paper is to review the available data on subinhibitory antimicrobial concentrations with an emphasis on clinical significance. Effects on bacterial growth, morphology, ultrastructure and virulence will be discussed. In addition, the effects of subinhibitory antimicrobial concentrations on host immune defences will be addressed.

\section{EFFECTS ON BACTERIAL GROWTH}

The MIC and MBC are useful terms to indicate antibacterial activity at high concentrations. The term minimum antibiotic concentration (MAC) was introduced to describe the effects of subinhibitory antimicrobial concentration on bacteria (2-4). The MAC is defined as the lowest antimicrobial concentration resulting in either a $90 \%$ (one $\log _{10}$ ) decrease in population compared to control, or a structural change visualized by light or electron microscopy (4). Various antimicrobials at subinhibitory concentrations have been reported to inhibit the rate of bacterial growth in vitro $(2-18)$. Since the number of infecting organisms may be important to the clinical outcome of infection, a 90\% reduction in bacterial population by subinhibitory antimicrobial concentrations could have important clinical consequences (15,19-21).

The clinical importance of bacterial load and how it relates to outcome was reported by Lyman et al (20). These investigators documented a statistically significant difference in the healing of infected skin lesions between groups with a low bacterial load (two $\log _{10}$ decrease from initial load) and high bacterial load (less than two $\log _{10}$ decrease from initial load). Louria (21) described a patient with bacteriologically diagnosed Staphylococcus aureus pneumonia whose clinical outcome was dependent upon bacterial load. When sputum cultures contained $3 \times 10^{6}$ staphylococci $/ \mathrm{mL}$ the patient was persistently febrile and clinically ill. However, upon reduction of bacterial load by slightly more than one $\log _{10}$, the clinical condition improved. More recently, Schaad et al (19) compared ceftriaxone with cefuroxime in the treatment of acute bacterial meningitis in 106 children. Although these investigators reported that clinical responses to therapy were similar in both treatment groups and all 106 children were cured, a statistically significant difference in moderate to profound hearing loss was reported in the cefuroxime group. Twelve per cent of patients in the cefuroxime-treated group, compared to $2 \%$ of patients in the ceftriaxone-treated group, maintained positive cerebrospinal fluid cultures after 18 to $36 \mathrm{~h}$ of therapy. Patients whose cerebrospinal fluid did not clear of bacteria by 18 to $36 \mathrm{~h}$ of therapy were more likely to acquire post therapy hearing loss. These limited clinical data suggest that the number of infecting organisms may relate to clinical outcome. By simply decreasing the bacterial inoculum by one $\log _{10}$ ( $90 \%$ reduction). subinhibitory antimicrobial concentrations could have important clinical consequences.

The MAC becomes more meaningful when it is expressed as a ratio with the MIC (MIC/MAC) rather than as an absolute value. The MIC/MAC ratio indicates the relative concentration range through which antimicrobial activity can be detected: the greater the ratio, the greater the range of antibacterial activity. For example, for strains of Staph aureus, the MIC/MAC ratios for various antimicrobials are: aminoglycosides 10; cephalosporins 8; chloramphenicol 6; macrolides 8; penicillins 8; and tetracyclines $12(2,4,11,12,15)$. This example suggests that against Staph aureus, tetracyclines and aminoglycosides display antibacterial effects over wider concentration ranges than the other drug groups. It should be noted that although the ratios for a given bacterial strain/antimicrobial combination are quite reproducible, many factors may influence the actual MIC/MAC ratio obtained. Although the mean MIC/ MAC ratio of all Staph aureus strains studied was 10 for aminoglycosides, the range obtained was 2 to $64(2,4$. $12,15)$. For cephalosporins, as stated above, the ratio is 8 but the range is 2 to 64 . Thus, the particular MIC/MAC ratio obtained depends not only on the antimicrobialorganism combination, but on the specific bacterial strain used. Pooling data describing MIC/MAC ratios should, however, be performed with caution as studies differ in media used, inoculum sizes, definitions of MAC and specific methodology used to assess MAC (eg, colony counts or turbidimetrically). Furthermore, these variables have not been studied in a comparative fashion to assess their individual effects on the MIC/MAC ratio.

Thus, the clinical usefulness of the mean MIC/MAC ratio for a given antimicrobial/bacterial species is limited at this time. The variability of MIC/MAC ratios for an individual antimicrobial against different strains of the same species is clear. Theoretically, however, an antimicrobial active at low concentrations should be therapeutically superior to a drug that is inactive below 


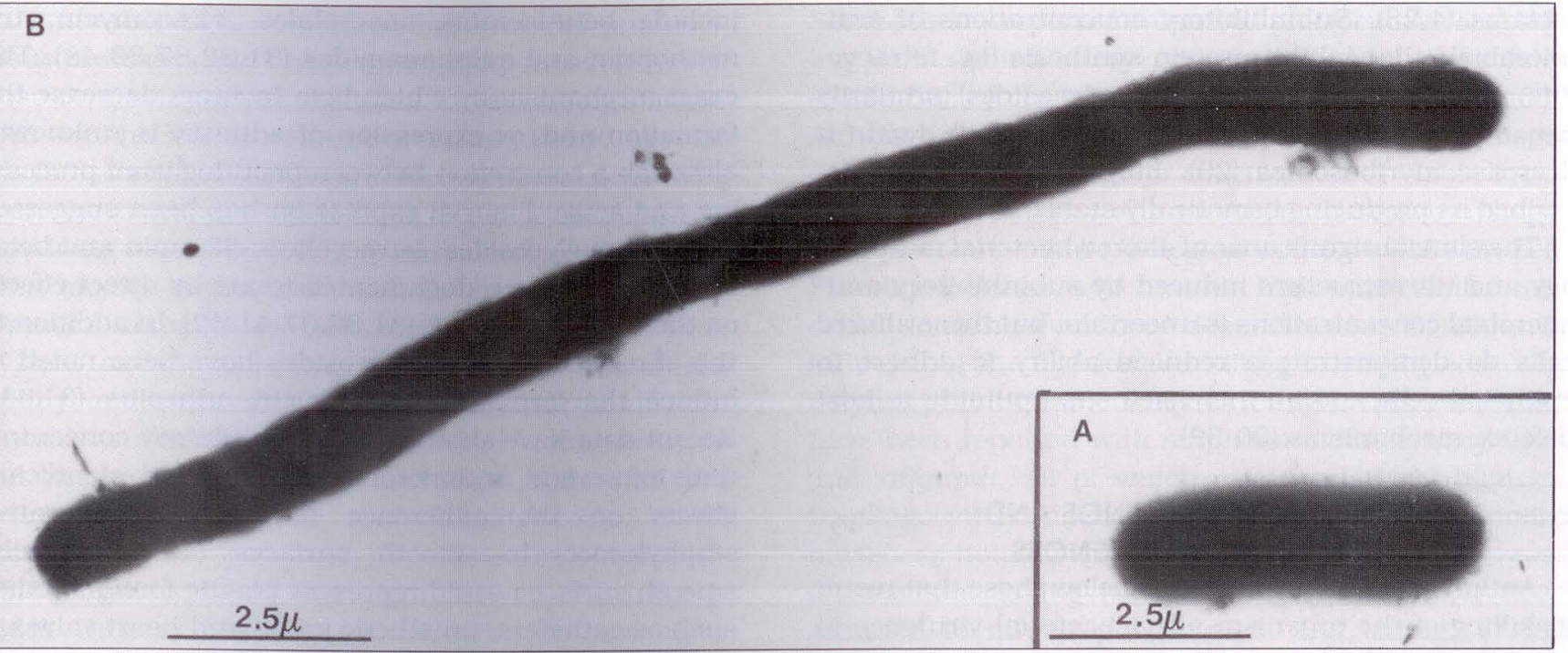

Figure 1) Electron micrograph showing $\mathbf{A}$ an Escherichia coli growing in Mueller-Hinton broth and $\mathbf{B}$ a filamentous E coli as a result of exposure to ampicillin at one-half minimal inhibitory concentration for $2 \mathrm{~h}$. Cells were stained with $2.5 \mathrm{mmol}$ phosphotungstic acid adjusted to $\mathrm{pH} 7.0$ with sodium hydroxide, and viewed on a Phillips model 201 electron microscope (magnification $\times 9000$ )

the MIC. The activity of an antimicrobial within the MIC/MAC range may be of interest, especially for drugs (eg, aminoglycosides) and combinations of drugs that are known to display concentration-dependent toxicity, and for which the lowest active dosage would therefore be desirable.

\section{EFFECTS ON MORPHOLOGY AND ULTRASTRUCTURE}

The morphological and ultrastructural changes induced by subinhibitory antimicrobial concentrations on bacteria have been observed using either light or electron microscopy $(2,4,22)$. The majority of reports describe the morphological changes induced by betalactams (penicillins and cephalosporins) with Grampositive cocci (usually Staph aureus) or Gram-negative bacilli (usually Escherichia coli) $(2,4,14,22-26)$.

The discovery of the functional role of penicillinbinding proteins (PBPs) for bacterial cell growth and morphological integrity in the presence of beta-lactam antimicrobials has provided a biochemical basis for the majority of morphological and ultrastructural changes. The change observed depends on which PBPs are affected (26). For example, with beta-lactams and $E$ coli: binding to PBP-1 causes cell lysis; binding to PBP-2 causes bacterial cells to round up; while binding to PBP-3 affects septum formation and leads to filamentation (26). The exact morphological changes induced by a particular antimicrobial/organism combination depends on the binding affinity of the antimicrobial to one or more of the PBPs, the rate of breakdown of the antimicrobial-PBP complex, and the concentration of the antimicrobial (26). Thus, the exact morphological and ultrastructural changes induced by a particular beta-lactam against a particular bacterium may not be consistent. Some generalities, however, can be made. Exposure of staphylococci to subinhibitory concentrations of beta-lactam antimicrobials results in the formation of abnormally large cells which are actually clusters of staphylococci with thickened cross-walls but without major alterations to outer cell walls (24). Thus, subinhibitory concentrations of beta-lactams inhibit lysis of cross-walls, preventing the separation of otherwise divided cells. Similar morphological effects have been documented with subinhibitory concentrations of beta-lactams and Streptococcus pneumoniae, Streptococcus pyogenes and Neisseria gonorrhoeae (4, 26).

Fewer data are available regarding the morphological and ultrastructural changes induced against Grampositive cocci by agents other than beta-lactams. Subinhibitory concentrations of rifampin, chloramphenicol, tetracycline and the macrolide antimicrobials cause thickening of the peripheral cell wall (4). Vancomycin induces similar morphological and ultrastructural changes against Gram-positive cocci as do betalactams (4).

Generally speaking, Gram-negative bacilli exposed to subinhibitory concentrations of beta-lactams become elongated and, in the absence of septation, form long filamentous cells $(2,14,22,23,26)$ (Figure 1). In addition, these cells show no signs of division (2). Ultrastructural changes induced by subinhibitory concentrations of beta-lactams against Gram-negative bacilli include a decrease in the density of ribosomes (2) and disruption of the outer membrane $(27,28)$.

Subinhibitory concentrations of fluoroquinolones, sulphonamides and trimethoprim produce similar morphological changes in Gram-negative bacilli as do beta- 
lactams $(4,28)$. Subinhibitory concentrations of antimicrobials that inhibit protein synthesis (eg, tetracycline, chloramphenicol and aminoglycosides) primarily cause elongation of Gram-negative bacilli with a decrease in ribosomes (29). Imipenem has been described as producing osmotically stable round cells (4).

The clinical significance of altered bacterial morphology and ultrastructure induced by subinhibitory antimicrobial concentrations is uncertain, but these altered cells do demonstrate a reduced ability to adhere to epithelial cells and an increased susceptibility to host defence mechanisms (30-32).

\section{EFFECTS ON VIRULENCE AND HOST IMMUNE DEFENCES}

Antimicrobial concentrations below those that result in killing of the organism affect bacterial virulence in several ways: changes in ability to adhere to epithelial cells; alterations in susceptibility to host defence mechanisms including phagocytosis, chemotaxis and complement-mediated immunity; and changes in toxin, plasmid or enzyme production (30-37).

The pathogenesis of infection at mucosal surfaces involves a number of steps, including adherence of bacteria to the epithelium followed by colonization, tissue damage and, in some cases, invasion and dissemination $(34,35)$. Bacterial adherence to epithelial cells is important for at least three reasons: to resist the cleansing action by solutes (such as urine and saliva) of the mucosal surface; to deliver toxin molecules in higher concentration to the toxin receptors on the cell membrane; and to promote attachment to target tissues within the host that are distant from the point of entry, eg, in shigellosis (34). Bacteria adhere to surfaces with specific ligand molecules (adhesins) which reside on bacterial surfaces and which interact with complementary molecules (receptors) on the surface of host epithelial cells $(31,32,34)$. The ability of microorganisms to adhere to epithelial cells is dependent on their ability to both synthesize and express the adhesin $(31,32)$. Fimbriae in Gram-negative bacteria and fimbrillae in Gram-positive bacteria are believed to be the most important surface adhesins or ligands responsible for attachment to mucosal surfaces (35).

Many studies document a decrease in bacterial adherence with subinhibitory concentrations of antimicrobials $(30,34,36-42)$. The majority of published data have tested $E$ coli, usually with uroepithelial cells (31,32,34,35,37-41). Antiadhesive effects are exerted by subinhibitory concentrations through three different ways: suppression of formation and/or expression of the surface adhesin in growing organisms; a direct effect on the bacterial surface; or formation of functionally aberrant adhesins $(30,31,39,41)$.

Antimicrobials at subinhibitory concentrations that have been reported to decrease bacterial adherence by decreasing formation and/or expression of adhesin, include beta-lactams, macrolides, vancomycin, trimethoprim and sulphonamides (31,32,37,39-41). The exact mechanism by which beta-lactams decrease the formation and/or expression of adhesin is unknown, although a connection between peptidoglycan processing and active fimbrial expression has been suggested (32). Aminoglycosides, tetracycline, rifampin and betalactams have been documented to act by direct effects on the bacterial surface $(31,32,37,41,42)$. In addition to this direct effect, aminoglycosides have been noted to induce the formation of aberrant adhesins $(31,41)$. Recent data have shown that subinhibitory concentrations of several antimicrobial agents exert significant effects on the adherence of coagulase negative staphylococci to smooth surfaces (43). Clinically, smooth surfaces could represent plastic foreign bodies such as catheters, prosthetic joints and heart valves.

Although the majority of studies have reported decreased bacterial adherence with subinhibitory antimicrobial concentrations, several have documented either increased bacterial adherence or conflicting data following treatment with subinhibitory concentrations $(4,43,44)$. Panhotra et al $(44)$ noted that while klebsiella strains grown in the presence of subinhibitory concentrations of gentamicin demonstrated reduced ad herence to uroepithelial cells, uroepithelial cells treated in vitro with subinhibitory concentrations of gentamicin or uroepithelial cells obtained from patients who had received gentamicin while hospitalized (thus, suprainhibitory concentrations) and subsequently incubated with klebsiella strains demonstrated increased adherence compared to controls (44). These investigators hypothesized that gentamicin may have altered antiadherence factors (such as uromucoid, urinary immunoglobulin, bladder mucopolysaccharide) present in the urinary tract. The significance of the subinhibitory antimicrobial concentration-induced increase in bacterial adherence is presently unknown.

The effect of subinhibitory antimicrobial concentrations on host defences has received considerable attention (45-49). The influence of subinhibitory antimicrobial concentrations on the interaction of microorganisms with phagocytes can be categorized into two types: first, subinhibitory antimicrobial concentrations may alter the microbe without killing it. thus changing its susceptibility to phagocytes and killing; and second, subinhibitory antimicrobial concentrations may alter functions of the phagocyte (chemotaxis, phagocytosis or microbicidal activity) by acting directly on the phagocytic cell $(6,30)$. The morphological and ultrastructural changes induced in microorganisms by subinhibitory antimicrobial concentrations have been discussed previously in this article and, thus, only the second type of interaction will be described.

Chemotaxis is the process by which phagocytes are attracted to the vicinity of pathogenic microorganisms 
via a number of factors including bacterial products, tissue proteases and complement components (48). The most commonly used methods for assessing chemotaxis are the Boyden chamber technique and agarose gels (50). Variable results are often obtained depending upon the method used $(45,50)$. Possible mechanisms explaining how subinhibitory antimicrobial concentrations modify chemotaxis include: impairment of adherence; competition for a chemotactic receptor; divalent cation chelation; modification of membrane fluidity; and inactivation of the chemoattractant (51). In general, subinhibitory antimicrobial concentrations and serum concentrations achieved with standard dosing of beta-lactam and aminoglycoside antimicrobials have minor or no effects on chemotaxis $(45,47)$. Nalidixic acid, fluoroquinolones and sulphonamides with or without trimethoprim do not affect chemotaxis in vitro $(47,52)$. While some agents such as erythromycin, chloramphenicol and clindamycin demonstrate variable effects, antimicrobial agents such as tetracycline, doxycycline, rifampin, nitrofurantoin and fusidic acid consistently inhibit phagocytic chemotaxis in vitro $(47,48)$. At present, no agreement can be found as to which in vitro method for determining chemotaxis approximates in vivo conditions.

Phagocytosis by polymorphonuclear leukocytes, an important defence mechanism against invading bacteria, can be modulated by different antimicrobials (50). Subinhibitory concentrations of most antimicrobials improve the phagocytic and intracellular killing activity of human polymorphonuclear leukocytes against bacteria that have been altered by pre-incubation with subinhibitory antimicrobial concentrations (53,61). An example is beta-lactam-induced filaments of Gramnegative bacilli, which are easily phagocytosed (59).

Conflicting results are available describing the direct effects of subinhibitory antimicrobial concentrations on the phagocytosis and intracellular killing of bacteria by polymorphonuclear leukocytes $(53,57)$. These discrepancies may be the result of a lack of standardized procedures for assessing these functions. Intracellular bacterial killing is mediated by two main mechanisms: oxygen-dependent and oxygen-independent (50). Oxygen-dependent mechanisms rely on toxic molecules produced as a result of the respiratory burst. Oxygenindependent mechanisms use lysozyme, lactoferrin and cationic proteins.

Beta-lactam antimicrobials and aminoglycosides have little or no direct effect on the phagocytosis or intracellular killing of bacteria by polymorphonuclear leukocytes (49). This may be due to poor penetration of beta-lactams and aminoglycosides into phagocytes (62). Macrolide antimicrobials (clindamycin, spiramycin, erythromycin) attain intracellular concentrations far higher than those in extracellular medium, but their effects on polymorphonuclear leukocyte phagocytosis and killing of bacteria are varied $(55,56,58,63)$.
Some studies reported enhanced phagocytosis and killing with subinhibitory concentrations of macrolides $(55,56,58)$, while others report little or no effect $(63)$. Although the entry of antimicrobial agents into phagocytes is a prerequisite for inactivation of viable intraphagocytic bacteria, antimicrobial uptake by phagocytes does not ensure biological activity within the cell. Fluoroquinolones, which attain high intracellular concentrations, have not been documented as significantly influencing the uptake and killing of staphylococci by polymorphonuclear leukocytes $(52,54)$. Variable results have been reported with sulphonamides, tetracyclines and rifampin, all of which attain relatively high intraphagocytic concentrations (45-47). Sulphonamides have been noted to enhance phagocytosis and decrease intracellular killing (45-48). Tetracyclines have been reported to inhibit phagocytosis and killing $(47,48)$. Rifampin has been documented to both increase and decrease intracellular killing $(45,64)$.

Summarizing these complex and often conflicting data and establishing clinical relevance are not easy tasks. Although it is clear that subinhibitory antimicrobial concentrations improve the phagocytic and intracellular killing activity of human polymorphonuclear leukocytes against bacteria that have been altered by pre-incubation with antimicrobials, the direct effects of subinhibitory antimicrobials on phagocytosis and intracellular killing of bacteria by polymorphonuclear leukocytes are conflicting and confusing. In addition, extrapolating these in vitro data to the clinical setting may not be valid. Treatment with antimicrobials appears to involve interactions of antimicrobial/organism, immune system/organism and antimicrobial/immune system. Carefully designed studies to define better the clinical relevance of antimicrobial effects on the immune system are required.

\section{ANIMAL STUDIES}

The effects of subinhibitory antimicrobial concentrations in animal models were first reported in the late 1970s. Zak and Kradolfer (65) infected rabbits intraperitoneally with either $E$ coli or Proteus mirabilis, and treated these animals with subinhibitory concentrations of beta-lactams or aminoglycosides (65). Upon analysis of peritoneal fluid, subinhibitory concentrations of both beta-lactams and aminoglycosides were noted to alter bacterial morphology and to decrease bacterial counts compared to controls. Zak and Kradolfer (65) also noted that subinhibitory concentrations of beta-lactams and aminoglycosides prolonged the survival rates of rabbits. Grimwood et al (66) used the rat lung model to evaluate subinhibitory concentrations of tobramycin, ciprofloxacin and ceftazidime on Pseudomonas aeruginosa exoenzyme expression and lung injury. The antimicrobial concentrations attained within the lungs ranged from one-twentieth to one-fifth of the Mic. Quantitative bacterial counts from rat lung 
homogenates were not different between antimicrobialtreated and control rats. Grimwood (66) documented reduced exoenzyme expression and decreased histological injury and, thus, protective effects, in the antimicrobial-treated group compared to the control group, and concluded that antimicrobial protection against Ps aeruginosa lung injury may involve the modulation of virulence factors. Geers and Baker (67) recently evaluated the ability of subinhibitory concentrations of aminoglycosides and beta-lactams to alter the pathogenicity of Ps aeruginosa in hamster tracheal explants. Subinhibitory concentrations of aminoglycosides but not beta-lactams protected hamster tracheal organ cultures from epithelial damage caused by mucoid and nonmucoid strains of PS aeruginosa. This protection by aminoglycosides occurred through inhibition of the release of toxic substances such as elastase and exotoxin A. Francioli and Glauser (68) recently investigated the effects of subinhibitory concentrations of penicillin against experimental Streptococcus intermedius endocarditis in rats. These investigators concluded that subinhibitory concentrations of penicillin prevented streptococcal endocarditis by mechanisms other than bacterial killing. Drake et al (69) concluded that subinhibitory antimicrobial concentrations decrease bacterial adherence and reduce infectivity in animal models of endocarditis.

\section{CLINICAL IMPLICATIONS}

The clinical significance of subinhibitory antimicrobial concentrations remains speculative. Whether some of the beneficial effects of long term, low dosage antimicrobial prophylaxis in women with recurrent urinary tract infections may be due to the effects of low urinary, vaginal and/or fecal antimicrobial concentrations is unclear. Subinhibitory antimicrobial concentrations may decrease bacterial adherence and may therefore reduce colonization of the anal canal, perineum, vagina, urethra and bladder (35). Redjeb et al (70) reported their experience with treating symptomatic urinary tract infections due to $E$ coli with very low dose ampicillin. The treatment group received $10 \mathrm{mg}$ ampicillin with $2 \mathrm{~L}$ of fluid daily, while the control group received $2 \mathrm{~L}$ of fluid without ampicillin. Of the 20 patients with at least $10^{5}$ colony forming units (cfu) $/ \mathrm{mL}$ of urine before treatment, $16(80 \%)$ had less than $10^{4}$ $\mathrm{cfu} / \mathrm{mL}$ and normal urinary leukocytes three to seven days after ampicillin treatment. Bacterial concentrations and urinary leukocytes persisted in the 18 controls. The dose of ampicillin (10 mg) used in this study resulted in urinary concentrations in most patients of approximately one-fifth to one-half of the MIC of the infecting organism. The prompt decrease in the number of bacteria in patients receiving $10 \mathrm{mg}$ ampicillin per day demonstrated that this dose produced significant antibacterial activity in the urine. Kristiansen et al (71) reported subinhibitory concentrations of lincomycin in saliva causing a marked decrease in the meningococcal counts of pharyngeal secretions in four meningococcal carriers. The authors concluded that the decreased counts were the result of decreased adherence of the organism. According to these limited data, at the present time, the clinical significance of subinhibitory antimicrobial concentrations in the treatment and prevention of infectious diseases is unclear.

Advances in the investigation of subinhibitory antimicrobial concentrations may provide in the future a clearer understanding of the molecular mechanisms by which antimicrobials exert their effects. This will potentially aid in design of antimicrobial dosing regimens $(17,72)$. It has been suggested that present dosing regimens, designed to maintain antimicrobial serum concentrations above the MIC of susceptible organisms for the majority of the dosing interval $(73,74)$, may not be optimal in terms of efficacy, toxicity or cost (74-76). Recent work has demonstrated that parameters other than the MIC, such as the post antibiotic effect and kill curves, should also be considered in the design of antimicrobial dosing regimens $(17,72)$. Post antibiotic effect has been documented to be a reproducible phenomenon (77), occurring at antimicrobial concentrations above and below the MIC (18-72), in biological fluids such as serum (78) and urine (79), and in vivo as well as in vitro (72). The clinical significance of post antibiotic effect has recently been demonstrated with aminoglycosides (80). Against Gram-negative bacillary pathogens, these antimicrobials produce concentration-dependent bacterial killing and post antibiotic effects lasting several hours (18). In addition, post antibiotic effects increase with increasing dosage (18, 72). These two factors have led to trials assessing once daily aminoglycoside dosing versus traditional, more frequent dosing (80).

The results of these preliminary studies suggest that once daily aminoglycoside dosing is as effective, and no more nephro- or ototoxic, than traditional dosing (80). It has been suggested that beta-lactams which, in con trast to aminoglycosides, do not produce concentration-dependent killing and tend to produce short post antibiotic effects against Gram-negative bacillary organisms, should be administered frequently or as continuous infusions (81).

The only effective way of investigating such complex effects as post antibiotic effect is to use subinhibitory antimicrobial concentrations, which allows assessment of antibacterial effects without producing excess killing.

One possible consequence of administering antimicrobials that yield subinhibitory concentrations in the blood or tissues is an increased risk of the emergence of resistant organisms. Several recent studies have addressed this issue (82-88). Although methodologies differ, most investigators assess development of resistance to subinhibitory antimicrobial concentrations by multiple passages of organisms to increasing 
antimicrobial concentrations, always at subinhibitory concentrations. MICs are assessed after each passage and compared before and after passaging has terminated. The results of these studies allow the following conclusions to be made about development of resistance: it is dependent upon the type of bacteria used; the particular strain tested; and the antimicrobial used. Watanakunakorn $(82,83)$ recently demonstrated that coagulase negative staphylococci were more likely to acquire resistance to teicoplanin and vancomycin than coagulase positive staphylococci $(82,83)$. In addition, Watanakunakorn $(82,83)$ reported that resistance was considerably more difficult to acquire with vancomycin than teicoplanin $(82,83)$. Studying Staph aureus and various Gram-negative bacilli with several fluoroquinolones, Aldridge et al (84) demonstrated that the acquisition of resistance was minor in general and strain dependent. Although resistance can be acquired with the use of subinhibitory antimicrobial concentrations, these newly resistant strains often revert back to

ACKNOWLEDGEMENTS: Dr Zhanel is the recipient of a postdoctoral research fellowship from the Pharmaceutical Manufacturers Association of Canada Health Research Foundation and the Medical Research Council of Canada. The authors thank Mrs Mary Wegrzyn for expert secretarial assistance and Mr Paul Hazelton for assistance in preparing the electron micrographs.

\section{REFERENCES}

1. Rolinson GN. Subinhibitory concentrations of antibiotics. J Antimicrob Chemother 1977;3:111-3.

2. Lorian V. Some effects of subinhibitory concentrations of antibiotics on bacteria. Bull NY Acad Med 1975:51:1046-55.

3. Washington JA. The effects and significance of subminimal inhibitory concentrations of antibiotics. Rev Infect Dis 1979;1:781-6.

4. Lorian V. Effect of low antibiotic concentrations on bacteria: Effects on ultrastructure, their virulence and susceptibility to immunodefenses. In: Lorian V, ed. Antibiotics in Laboratory Medicine, 2nd edn. Baltimore: Williams and Wilkins, 1986:515-36.

5. Fuursted K. Synergism and mechanism of subinhibitory concentrations of streptomycin on Streptococcus faecalis. Acta Pathol Microbiol Immunol Scand 1989:97:27-32.

6. Fuursted K. Further studies on the postantibiotic effect and synergism in two strains of Streptococcus faecalis. Acta Pathol Microbiol Immunol Scand 1989:97:33-7.

7. Zanon U. Subinhibitory levels of antibiotics. J Antimicrob Chemother 1977;3:106-7.

8. Arpi M. Time-kill studies and synergy testing of broad spectrum antibiotics against blood culture isolates. Chemotherapy 1988:34:393-400.

9. Miller MH, Feinstein SA, Chow RT. Early effects of beta-lactams on aminoglycoside uptake, bactericidal rates, and turbidimetrically measured growth inhibition in Pseudomonas aeruginosa. Antimicrob Agents Chemother 1987;31:108-10.

10. Haller I. Comprehensive evaluation of ciprofloxacin in combination with beta-lactam antibiotics against Enterobacteriaceae and Pseudomonas aeruginosa. susceptibility once antimicrobial pressure has been removed (4). In addition, bacterial strains that have been made resistant to antimicrobials often demonstrate reduced virulence, manifested by a slower growth rate and reduced expression of enzymes (4). Finally, it should be stated that the in vitro studies assessing the incidence of resistance to subinhibitory antimicrobial concentrations do not consider the immune response.

\section{CONCLUSIONS}

Although subinhibitory antimicrobial concentrations produce a variety of effects including altering bacterial morphology and growth, affecting bacterial virulence factors, and altering bacterial susceptibility to host immune defences, the clinical significance of these effects in patients with infectious diseases is presently unclear. The major future role of subinhibitory antimicrobial concentrations will be to define more fully, at a molecular level, how antimicrobials exert their antibacterial effects.

Arzneimittelforsch 1986;36:226-9.

11. Ezrow L, Scaeanu C, Dabydeen H. Range of antibacterial activity of antibiotics at subminimal inhibitory concentrations: The ratio of minimal inhibitory concentration to minimal antibiotic concentration. Rev Infect Dis 1979:1:821-4.

12. Kitzis MD, Bouanchaud DH, Acar JF. Recovery period and the exposure of bacteria to subminimal inhibitory concentrations of antibiotics. Rev Infect Dis 1979:1:825-31.

13. Shah PM, Heetderks G, Stille W. Activity of amikacin at sub-inhibitory levels. J Antimicrob Chemother 1976:2:97-100.

14. Andreana A, Perna P, Utili R, Dilillo M, Ruggiero G. Increased phagocytosis and killing of Escherichia coli treated with subinhibitory concentrations of cefamandole and gentamicin in isolated rat livers. Antimicrob Agents Chemother 1986;25:182-6.

15. Lorian V, DeFreitas CC. Minimal antibiotic concentrations of aminoglycosides and beta-lactam antibiotics for some Gram-negative bacilli and Gram-positive cocci. J Infect Dis 1979;139:599-603.

16. Kitzis MD, Gutmann L, Acar JF. Recovery period after exposure of Staphylcoccus aureus to sub-inhibitory and bactericidal concentrations of rifampin: Clinical implications. J Antimicrob Chemother 1984; 13:1-5.

17. Craig WA, Gudmundsson S. The postantibiotic effect. In: Lorian V, ed. Antibiotics in Laboratory Medicine, 2nd edn. Baltimore: Williams and Wilkins, 1986:515-36.

18. Zhanel GG, Hoban DJ, Davidson RJ. Antimicrobial activity of subinhibitory concentrations of aminoglycosides against Pseudomonas aeruginosa as determined by the killing curve method and the postantibiotic effect (PAE). Chemotherapy 1991;37:114-20.

19. Schaad UB, Suter S, Gianella-Borradori A, et al. A comparison of ceftriaxone and cefuroxime for the treatment of bacterial meningitis in children. N Engl J Med 1990;322:141-7.

20. Lyman IR, Tenery JH, Basson RP. Correlation between decrease in bacterial load and rate of wound healing. Surg Gynecol Obstet 1970;130:616-21.

21. Louria DB. Uses of quantitative analyses of bacterial 
populations in sputum. JAMA 1962;182:106-10.

22. Zimmerman SB, Stapley EO. Relative morphological effects induced by cefoxitin and other beta-lactam antibiotics in vitro. Antimicrob Agents Chemother 1976:9:318-26.

23. Labro MT, Pochet I, Babin-Chevaye C, Hakim J. Effect of ceftriaxone-induced alterations of bacteria on neutrophil bactericidal function. J Antimicrob Chemother 1987:20:857-69.

24. Lorian V. Some effects of subinhibitory concentrations of penicillin on the structure and division of staphylococci. Antimicrob Agents Chemother 1975;7:864-70.

25. Taschner PEM, Ypenburg N, Spratt BG. Woldringh CL. An amino acid substitution in penicillin-binding protein 3 creates pointed polar caps in Escherichia coli. J Bacteriol 1988; 170:4828-37.

26. Hamilton-Miller JMT. Microbiological investigation of cephalosporins. Drugs 1987;34(Suppl 2):23-43.

27. Stubner G, Dalhoff A, Voigt WH. Bacteriological and ultrastructural studies on the effect of subinhibitory beta-lactam concentrations on intraphagocytic killing of Pseudomonas aeruginosa by human polymorphonuclear leukocytes. Arzneimittelforsch 1986;36:899-904.

28. Suerbaum S, Leying H, Kroll HP, Gmeiner J, Opferkuch W. Influence of beta-lactam antibiotics and ciprofloxacin on cell envelope of Escherichia coli. Antimicrob Agents Chemother 1987;31:1106-10.

29. Pulvertaft RJV. The effects of antibiotics on growing cultures of Bacterium coli. J Pathol Bacteriol 1952;64:75-89.

30. Shibl AM. Influence of subinhibitory concentrations of antibiotics on virulence of staphylococci. Rev Infect Dis 1987;9:704-12.

31. Schifferli DM, Beachey EH. Bacterial adhesion: Modulation by antibiotics which perturb protein synthesis. Antmicrob Agents Chemother 1988;32:1603-8.

32. Schifferli DM, Beachey EH. Bacterial adhesion: Modulation by antibiotics with primary targets other than protein synthesis. Antimicrob Agents Chemother 1988:32:1609-13.

33. Fu KP, Grace ME, Hsiao CL, Hung PP. Elimination of antibiotic-resistant plasmids by quinolone antibiotics. Chemotherapy 1988:34:415-8.

34. Shibl AM. Effect of antibiotics on adherence of microorganisms to epithelial cell surfaces. Rev Infect Dis 1985;7:51-65.

35. Reid G, Sobel JD. Bacterial adherence in the pathogenesis of urinary tract infection: A review. Rev Infect Dis 1987:9:470-87.

36. Absolom DR. The role of bacterial hydrophobicity in infection: Bacterial adhesion and phagocytic ingestion. Can J Microbiol 1988;34:287-98.

37. Sandberg T, Stenquist K, Svanborg-Eden C. Effects of subminimal inhibitory concentrations of ampicillin, chloramphenicol and nitrofurantoin on the attachment of Escherichia coli to human uroepithelial cells in vitro. Rev Infect Dis 1979;1:838-44.

38. Bassaris HP, Lianou PE, Votta EG, Papavassiliou JT. Effects of subinhibitory concentrations of cefotaxime on adhesion and polymorphonuclear leukocyte function with Gram-negative bacteria. J Antimicrob Chemother 1984; 14:91-6.

39. Dean EA, Kessler RE. Quantitation of effects of subinhibitory concentrations of trimethoprim on $\mathrm{P}$ fimbria expression and in vitro adhesiveness of uropathogenic Escherichia coli. J Clin Microbiol 1988;26:25-30.

40. Klein U, Pawelzik M, Opferkuch W. Influence of beta-lactam antibiotics fosfomycin and vancomycin on the adherence (hemagglutination) of Escherichia coli containing different adhesin. Chemotherapy 1985;31:138-45.

41. Ofek I, Beachey EH, Eisenstein BI, Alkan ML, Sharon N. Suppression of bacterial adherence by subminimal inhibitory concentrations of beta-lactam and aminoglycoside antibiotics. Rev Infect Dis 1979;1:832-7.

42. Lantz MS, Ray T, Krishnasami S, Pearson DE. Subinhibitory concentrations of tetracycline alter fibrinogen binding Bacteroides intermedius. Antimicrob Agents Chemother 1987;31:1915-8.

43. Schadow KH, Simpson WA, Christensen GD. Characterisitics of adherence to plastic tissue culture plates of coagulase-negative staphylococci exposed to subinhibitory concentrations of antimicrobial agents. J Infect Dis 1988;157:71-7.

44. Panhotra BR, Bhat SL, Mahajan B. Effect of subinhibitory concentration of gentamicin on adherence of Klebsiella aerogenes to uroepithelial cell in vitro. Ind J Med Res 1988;88:130-3.

45. Korzeniowski OM. Effects of antibiotics on the mammalian immune system. Infect Dis Clin North Am 1989:3:469-78.

46. Hand WL, King-Thompson NL, Steinberg TH. Interactions of antibiotics and phagocytes. J Antimicrob Chemother 1983:12(Suppl C):1-11.

47. Forsgren A. Antimicrobial agents and host defense. Scand J Infect Dis 1984;43:24-33.

48. Hauser WE, Remington JS. Effect of antibiotics on the immune response. Am J Med 1982;72:711-6.

49. Mandell LA. Effects of antimicrobial and antineoplastic drugs on the phagocytic and microbicidal function of the polymorphonuclear leukocyte. Rev Infect Dis 1982;4:683-97.

50. Sawyer DW, Donowitz GR, Mandell GL. Polymorphonuclear neutrophils: An effective antimicrobial force. Rev Infect Dis 1989;2 (Suppl 7):S1532-44.

51. Van der Auwera P, Husson M. Influence of rifampin and ansamycin on motility and adherence of human neutrophils studied in vitro. Antimicrob Chemother 1989;24:347-53.

52. Boogaerts MA, Malbrain S, Scheers W, Verwilghen RL. Effects of quinolones on granulocyte function in vitro. Infection 1986;14(Suppl 4):S258-62.

53. Raponi G, Vreede RW, Rozenberg-Arska M, et al. The influence of subminimal inhibitory concentrations of netilmicin and ceftriaxone on the interaction of Escherichia coli with host defenses. J Antimicrob Chemother 1989;23:565-76.

54. Pascual A, Martinez-Martinez L, Perea EJ. Effect of ciprofloxacin and ofloxacin on human polymorphonuclear leukocyte activity against staphylococci. Chemotherapy 1989;35:17-22.

55. Veringa EM, Verhoef J. Clindamycin at subinhibitory concentrations enhances antibody and complement dependent phagocytosis by human polymorphonuclear leukocytes of Staphylococcus aureus. Chemotherapy 1987:33:243-9.

56. Bassaris HP, Lianou PE. Papavassilioa JT. Interaction of subminimal inhibitory concentrations of clindamycin and Escherichia coli: Effects on adhesion and polymorphonuclear leukocyte function. J Antimicrob Chemother 1984; 13:361-7.

57. Watanable Y, Tawara S, Mine Y, Kikuchi H. Synergism of cephalosporins at subinhibitory concentrations and polymorphonuclear leukocytes on phagocytic killing of 
Escherichia coli and its mode of action. Antibiotics 1986;39:294-303.

58. Veringa EM, Lambe DW, Ferguson DA, Verhoef J. Enhancement of opsonophagocytosis of Bacteroides species by clindamycin in subinhibitory concentrations. J Antimicrob Chemother 1989:23:577-87.

59. Lorian V, Atkinson B. Bactericidal effect of polymorphonuclear neutrophils on antibiotic-induced filaments of Gram-negative bacilli. J Infect Dis 1984;149:719-27.

60. Labro MT, Pochet I, Babin-Chevaye C, Hakin J. Effect of ceftriaxone-induced alterations of bacteria on neutrophil bactericidal function. J Antimicrob Chemother 1987:20:857-69.

61. Dalhoff A, Stubner G. Comparative analysis of the antimicrobial action of polymorphonuclear leukocytes in vitro, ex vivo and in vivo. J Antimicrob Chemother 1985:15(Suppl A):283-91.

62. Schwab JC, Mandell GL. The importance of penetration of antimicrobial agents into cells. Infect Dis Clin North Am 1989:3:461-7.

63. Labro MT, Benna JE, Babin-Chevaye C. Comparison of the in vitro effect of several macrolides on the oxidative burst of human neutrophils. J Antimicrob Chemother 1989;24:561-72.

64. Hand WL, King-Thompson NL. Contrasts between phagocytic antibiotic uptake and subsequent intracellular bactericidal activity. Antimicrob Agents Chemother 1986;29:135-40.

65. Zak O, Kradolfer F. Effects of subminimal inhibitory concentrations of antibiotics in experimental infections. Rev Infect Dis 1979;1:862-79.

66. Grimwood K, To M, Rabin HR, Woods DE. Subinhibitory antibiotics reduce Pseudomonas aeruginosa tissue injury in the rat lung model. J Antimicrob Chemother 1989:24:937-45.

67. Geers TA, Baker NR. The effect of sublethal levels of antibiotics on the pathogenicity of Pseudomonas aeruginosa for tracheal tissue. J Antimicrob Chemother 1987;19:569-78.

68. Francioli P. Glauser MP. Successful prophylaxis of experimental streptococcal endocarditis with single doses of sublethal concentrations of penicillin. J Antimicrob Chemother 1985;15(Suppl A):297-302.

69. Drake TA, Scheld WM, Sande MA. Effects of sub-bactericidal concentrations of antibiotics in experimental models of endocarditis. J Antimicrob Chemother 1985;15(Suppl A):293-6.

70. Redjeb SB, Slim A, Horchani A, Zmerilli S, Boujnah A, Lorian $V$. Effects of ten milligrains of ampicillin per day on urinary tract infections. Antimicrob Agents Chemother 1982:22:1084-6.

71. Kristiansen BE, Rustad L, Spanne O, Bjorvath B. Effect of subminimal inhibitory concentrations of antimicrobial agents on the piliation and adherence of Neisseria meningitidis. Antimicrob Agents Chemother 1983:24:731-4.

72. Zhanel GG, Hoban DJ, Harding GKM. The postantibiotic effect: A review of in-vitro and in-vivo data. DICP Ann Pharmacother 1991:25:153-63.

73. Vogelman B, Craig WA. Kinetics of antimicrobial activity. J Pediatr 1986;108:835-40.

74. Neu HC. Current practices of antimicrobial dosing. Rev Infect Dis 1981:3:12-18.

75. Eagle H, Fleischman R, Musselman AD. Effect of schedule of administration on the therapeutic efficacy of penicillin. Am J Med 1950:9:280-99.

76. Eagle H, Fleischman R, Levi M. On the duration of penicillin action in relation to its concentration in serum. J Lab Clin Med 1953:41:122-32.

77. Zhanel GG. Davidson RJ, Hoban DJ. Reproducibility of the in-vitro postantibiotic effect (PAE) using fluoroquinolones against Staphylococcus aureus. J Antimicrob Chemother 1990;26:724-6.

78. Davidson RJ, Zhanel GG, Hoban DJ. Human serum enhances the postantibiotic effect (PAE) of fluoroquinolones against Staphylococcus aureus. Antimicrob Agents Chemother 1991:35:1261-3.

79. Zhanel GG, Karlowsky JA, Davidson RJ, Hoban DJ. Influence of human urine on the postantibiotic effect (PAE) of ciprofloxacin against Escherichia coli. Chemotherapy 1991;37:218-23.

80. Zhanel GG, Ariano RE. Once daily aminoglycoside dosing: Maintained efficacy with reduced nephrotoxicity? Renal Fail. (In press)

81. Yourassowsky E, Van der Linden MP, Crokaert F. One shot of high dose amikacin: A working hypothesis. Chemotherapy 1990;36:1-7.

82. Watanakunakorn C. In-vitro induction of resistance in coagulase-negative staphylococci to vancomycin and teicoplanin. J Antimicrob Chemother 1988;22:321-4.

83. Watanakunakorn C. In-vitro selection of resistance of Staphylococcus aureus to teicoplanin and vancomycin. J Antimicrob Chemother 1990;25:69-72.

84. Aldridge KE, Henderberg A, Gebbia K, Schiro DD, Janney A, Sanders CV. Lomefloxacin, a new fluoroquinolone. Studies on in-vitro antimicrobial spectrum, potency and development of resistance. Diagn Microbiol Infect Dis 1989;12:221-33.

85. Treharne JD, Yearsley PJ, Ballard RC. In-vitro studies of Chlamydia trachomatis susceptibility and resistance to rifampin and rifabutin. Antimicrob Agent Chemother 1989;33:1393-4

86. French GL, Ling J, Ling T, Hui YW. Susceptibility of Hong Kong isolates of methicillin-resistant Staphylococcus aureus to antimicrobial agents. J Antimicrob Chemother 1988;21:581-8.

87. Korting HC, Lukas A. Decrease of antimicrobial susceptibility of gonococci to newer quinolones after repeated exposition to subinhibitory concentrations in vitro. Infection 1989:17:(Suppl 1):6-10.

88. Daikos GL, Jackson GG, Lolans VT, Livermore DM. Adaptive resistance to aminoglycoside antibiotics from first-exposure down-regulation. J Infect Dis 1990; 162:414-20. 


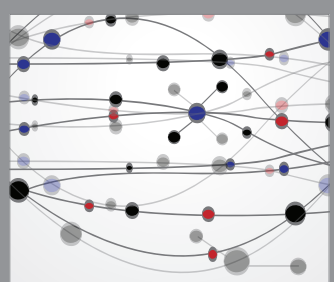

The Scientific World Journal
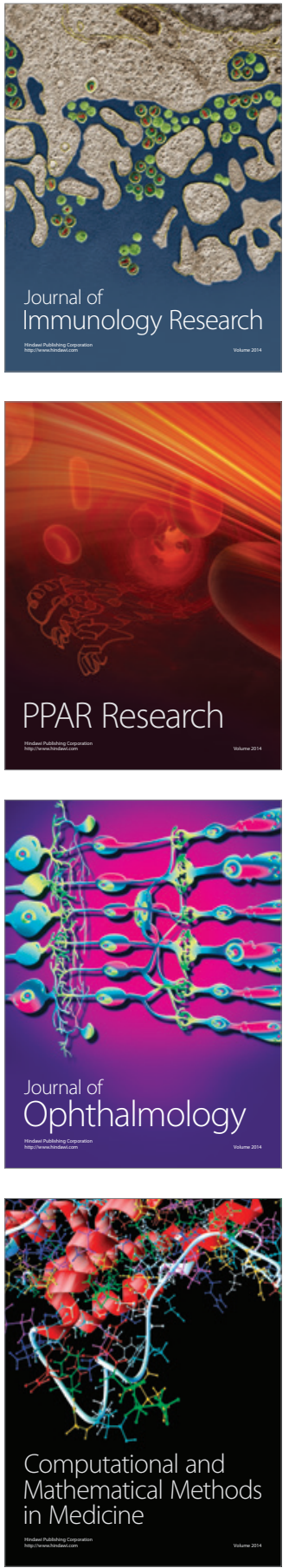

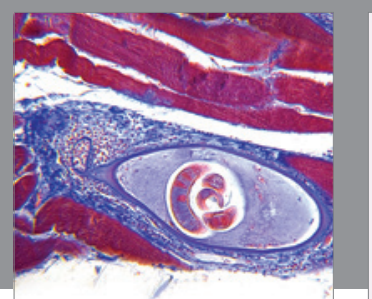

Gastroenterology Research and Practice

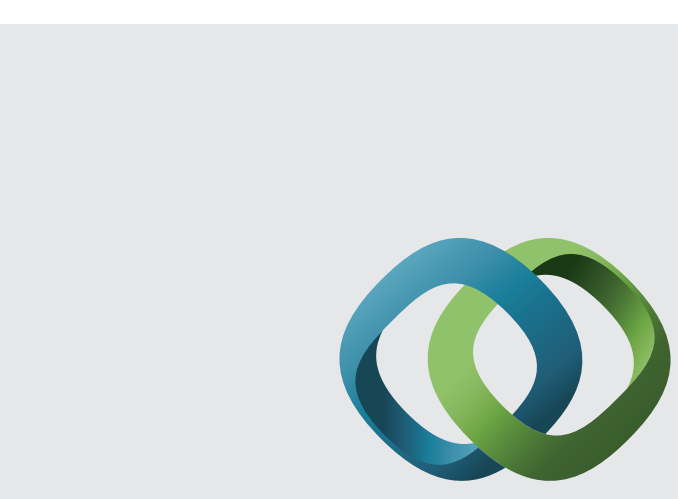

\section{Hindawi}

Submit your manuscripts at

http://www.hindawi.com
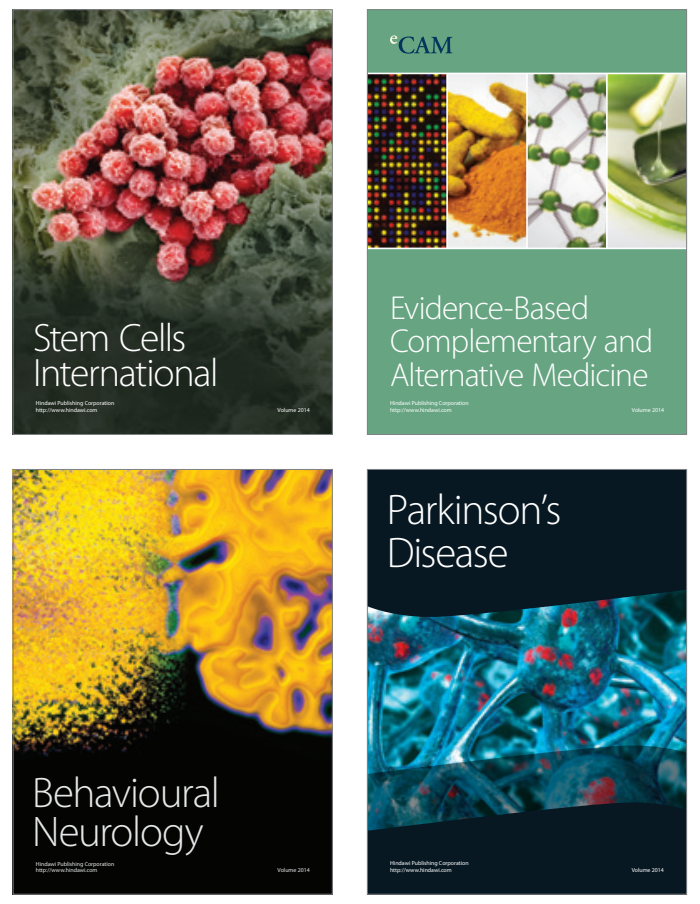
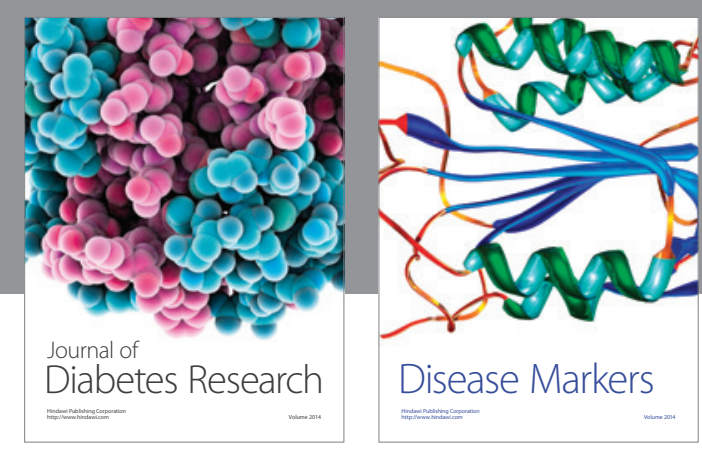

Disease Markers
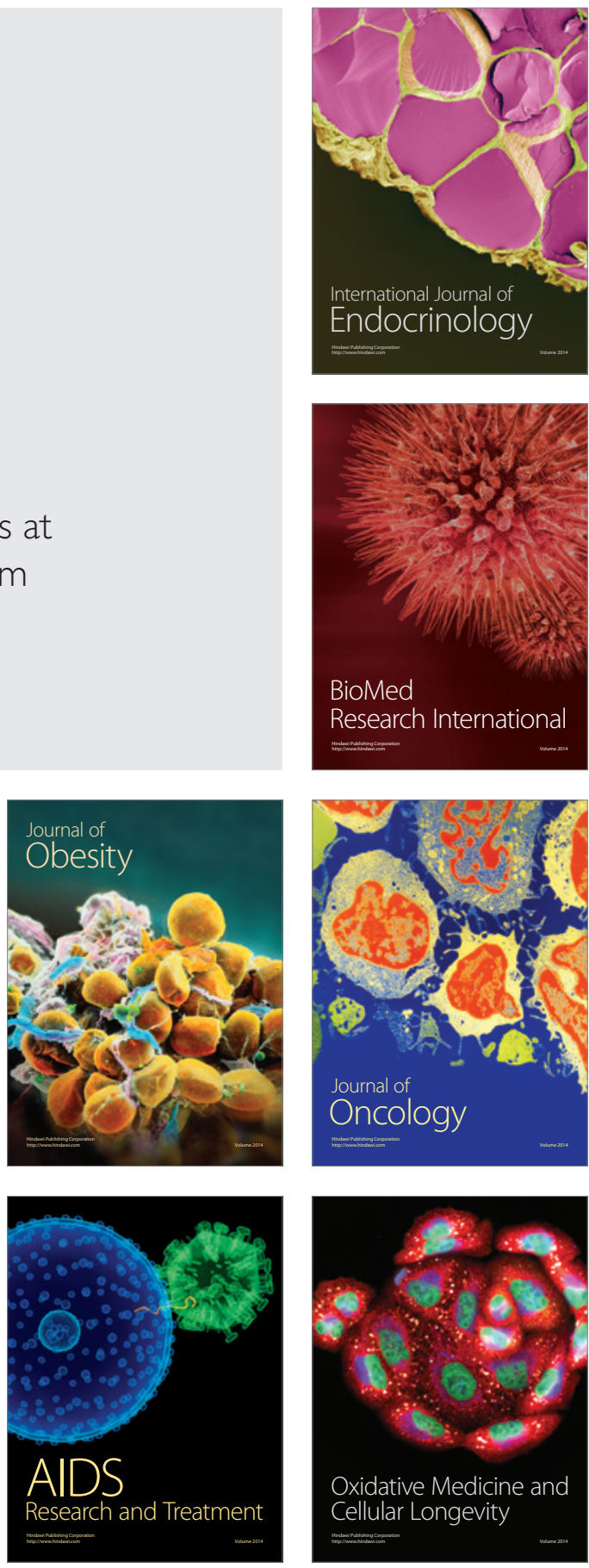